\title{
Evolutionary transitions in body plan and reproductive mode alter maintenance metabolism in squamates
}

\author{
Lin Zhang ${ }^{1,2}$, Kun Guo', Guang-Zheng Zhang ${ }^{1}$, Long-Hui Lin² and Xiang Ji ${ }^{1 *}$
}

\begin{abstract}
Background: Energy (resources) acquired by animals should be allocated towards competing demands, maintenance, growth, reproduction and fat storage. Reproduction has the second lowest priority in energy allocation and only is allowed after meeting the energetic demands for maintenance and growth. This hierarchical allocation of energy suggests the hypothesis that species or taxa with high maintenance costs would be less likely to invest more energy in reproduction or to evolve an energetically more expensive mode of reproduction. Here, we used data on standard metabolic rate so far reported for 196 species of squamates to test this hypothesis.

Results: We found that maintenance costs were lower in snakes than in lizards, and that the costs were lower in viviparous species than in oviparous species. As snakes generally invest more energy per reproductive episode than lizards, and viviparity is an energetically more expensive mode of reproduction than oviparity, our results are consistent with the hypothesis tested.

Conclusion: The transition from lizard-like to snake-like body form and the transition from oviparity to viviparity are major evolutionary transitions in vertebrates, which likely alter many aspects of biology of the organisms involved. Our study is the first to demonstrate that evolutionary transitions in body plan and reproductive mode alter maintenance metabolism in squamates.
\end{abstract}

Keywords: Body plan, Maintenance metabolism, Reproductive mode, Squamates, Standard metabolic rate

\section{Background}

Metabolism is one of the most fundamental biological processes, encompassing all of the reactions catalyzed by enzymes to generate and use energy; metabolic rate is the most fundamental biological rate because it is the rate of energy uptake, transformation and allocation and, as such, is integrally related to the pace of life $[1,2]$. In the case of animals, energy acquired by them will be allocated between two main competing demands, maintenance and production. Maintenance costs include the energy costs for basal (for endotherms) or standard (for ectotherms) metabolism and other activities essential for the continuity of an individual's life, and energy allocated to production hierarchically supports somatic tissue growth, reproduction and fat storage [3-6]. Reproduction is not essential for the survival

\footnotetext{
* Correspondence: xji@mail.hz.zj.cn

${ }^{1}$ Jiangsu Key Laboratory for Biodiversity and Biotechnology, College of Life

Sciences, Nanjing Normal University, Nanjing, Jiangsu 210023, China

Full list of author information is available at the end of the article
}

of an individual organism but it is important to reproduce for individual fitness and the continuity of populations and species. Earlier studies have showed that reproduction has the second lowest priority in energy allocation and only is allowed after the fulfillment of energetic requirements for maintenance and growth [6-10]. This hierarchical allocation of energy, when coupled with the fact that low energy costs for maintenance can translate into an increased potential to allocate more energy in reproduction, suggests the hypothesis that species or taxa with high maintenance costs would be less likely to invest more energy in reproduction or to evolve an energetically expensive mode of reproduction. To test this hypothesis, one needs to compare maintenance costs between animals that differ in reproductive investment or reproductive mode, best by means of using a group of animals spanning a relatively wide range of life-history and ecological strategies so it will be possible to draw some general conclusions. 
Here, we used standard metabolic rate (SMR) data so far reported for 196 species of squamates, of which 128 (80 lizards and 48 snakes) are oviparous and 68 (35 lizards and 33 snakes) are viviparous (Additional file 1: Table S1), to test the above hypothesis. When compared to lizards, snakes generally invest more energy in reproduction per episode and thus have a relatively higher clutch mass [11-13]. Viviparity is an energetically expensive mode of reproduction not only because the physiological cost of supporting a litter is an important component of reproductive effort, but also because a shift in thermal ecology (longer basking periods and higher body temperatures) may elevate maternal metabolism, provoke postpartum emaciation and increase exposure of females to predators [14-16]. Thus, if the above hypothesis is true, it should follow that maintenance costs are lower in snakes than in lizards, and that the costs are lower in viviparous species than in oviparous species.

\section{Methods}

We performed a bibliographic search for data on SMR, body mass and temperature (at which SMR was measured) reported for 196 species of squamate reptiles (115 lizards of the families Agamidae, Anniellidae, Anguidae, Cordylidae, Crotaphytidae, Dactyloidae, Gekkonidae, Iguanidae, Lacertidae, Liolaemidae, Phrynosomatidae, Pygopodidae, Scincidae, Sphaerodactylidae, Teiidae, Varanidae and Xantusiidae, and 81 snakes of the families Acrochordiae, Boidae, Colubridae, Elapidae, Pythonidae and Viperidae). To do that, we searched for references as thoroughly as possible from the Google Scholar and Web of Science, using the following keywords, lizard, metabolic rate, reptile, resting metabolic rate, squamate, standard metabolic rate and snake. We made great efforts to ensure that: (1) animals were fasted, inactive and measured at temperatures allowing normal activity but not during the breeding season (thus not allowing to address sex-specific rates in individual species); (2) thermal acclimation under laboratory conditions was brief; and (3) only data from the most well designed experiment were used in the case that more than one dataset was available for a species. We used the Reptile Database (www.reptile-database. org, accessed November 20, 2017) to check species name, excluding the data from synonyms and including the data from species risen from subspecies. Our dataset covered body masses from $0.4 \mathrm{~g}$ (Sphaerodactylus beattyi) to $16,150 \mathrm{~g}$ (Python sebae), and temperatures from $20{ }^{\circ} \mathrm{C}$ to $40{ }^{\circ} \mathrm{C}$ (Additional file 1: Table S1).

All data were transformed to natural logarithms prior to further analyses. We followed a method described by Brown et al. [1] to calculate temperature-corrected SMR $\left[\mathrm{tSMR}=\ln \left(\mathrm{B}_{0}\right)+b \ln \mathrm{M}\right]$ and mass-corrected SMR [mSMR $\left.=\ln \left(\mathrm{B}_{0}\right)-\mathrm{E}(1 / \mathrm{kT})\right]$, where $\mathrm{B}_{0}$ is a normalization constant independent of body size and temperature, $b$ is the allometric exponent, $M$ is body mass, $E$ is the activation energy, $\mathrm{k}$ is the Boltzmann's constant, and $\mathrm{T}$ is absolute temperature in $\mathrm{K}$, thereby controlling both temperature and body mass and getting the residual SMR. We used both ordinary least squares (OLS) and phylogenetic generalized least squares (PGLS) regressions implemented in $\mathrm{R}$ 3.3.0 [17] with the packages rms [18] and caper [19] to test whether relationships between selected pairs of variables were significant. The Akaike's Information Criterion (AIC) and the likelihood-ratio test (LRT) were used to assess the adequacy of models tested [20]. We performed PGLS to account for the non-independence of the data due to the shared evolutionary history of species. To do that, we constructed a phylogeny for the 196 species using Mesquite 3.04 [21] based on the relations at the species-level [22]. We followed a method described by Martins and Garland [23] to set branch lengths to 1 and used Mesquite 3.04 to reconstruct the ancestral states for the traits analyzed. Phylogenetic signal was measured by Pagel's lambda $(\lambda)$. Lambda values of or near 0 indicate phylogenetic independence; $\lambda$ values of or near 1 indicate that the variable is fully explained by evolutionary history and thus shows the maximal strength of phylogenetic signal [24, 25]. The results from the phylogeny with variable branch lengths [26] were the same as those from the phylogeny with equal branch lengths (Additional file 2: Tables S2, Additional file 3: Table S3, Additional file 4: Table S4, Additional file 5: Table S5, Additional file 6: Table S6). Therefore, we present the results using equal branch lengths so as to include 25 species of which sequences for reconstructing the phylogeny were either unavailable or incomplete. We used mSMR or tSMR as the response variable, and reproductive mode (oviparity versus viviparity), animal clade (lizards versus snakes) and temperature (for mSMR) or body mass (for tSMR) as the explanatory variables to test if the two response variables differed between oviparous and viviparous species and between lizards and snakes.

To better explore directionality between transitions in reproductive mode or body plan and maintenance metabolism, we performed phylogenetic confirmatory path analyses [27] based on nine candidate path models in R 3.3.0 [17] with the package phylopath [28]. We ranked all candidate models based on their C-statistic Information Criterion (CICc) and selected the best model with $\Delta \mathrm{CICc} \leq 2$ [27].

\section{Results}

Our reconstruction of evolutionary changes in metabolic variables shows strong positive relationships between metabolic rate and body mass (SMR: $r^{2}=0.88, F_{1,194}=1410.91$, $P<0.0001$ t tSMR: $\left.r^{2}=0.88, F_{1,194}=1407.94, P<0.0001\right)$, 


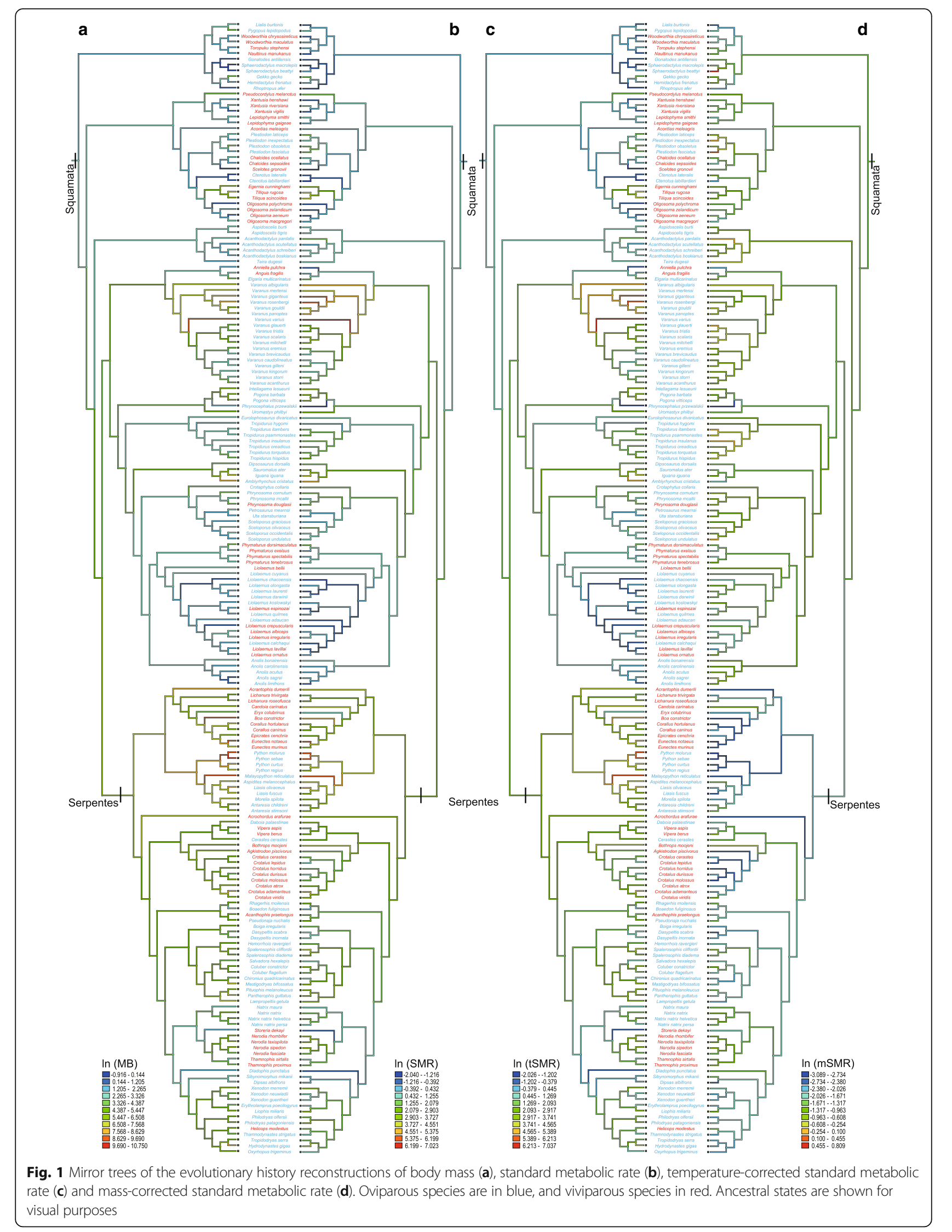


Table 1 Statistics describing the relationships shown in Fig. 1. Models were fitted using both OLS and PGLS regressions

\begin{tabular}{|c|c|c|c|c|c|c|c|c|}
\hline Model & $N$ & Slope $( \pm$ SE) & $r^{2}$ & $\lambda(95 \% \mathrm{Cl})$ & AIC & In likelihood & $F_{1,194}$ & $P$-value \\
\hline \multicolumn{9}{|c|}{ tSMR vs body mass } \\
\hline \multirow[t]{2}{*}{ OLS } & 196 & $0.85(0.02)^{* *}$ & 0.91 & & 316.2 & -153.5 & 1407.97 & $<0.001$ \\
\hline & 196 & $0.76(0.02)^{* *}$ & 0.88 & 0 & 314.6 & -151.3 & 1408.00 & $<0.001$ \\
\hline \multirow[t]{2}{*}{ PGLS } & 196 & $0.85(0.03)^{* *}$ & 0.86 & $0.61(0.51 / 0.91)$ & 308.8 & $-148.4^{a}$ & 1113.50 & $<0.001$ \\
\hline & 196 & $0.87(0.03)^{* *}$ & 0.79 & 1 & 312.9 & -150.5 & 716.21 & $<0.001$ \\
\hline \multicolumn{9}{|c|}{ mSMR vs temperature } \\
\hline \multirow[t]{2}{*}{ OLS } & 196 & $-0.42(0.08)^{* *}$ & 0.41 & & 311.8 & -150.9 & 21.97 & $<0.001$ \\
\hline & 196 & $-0.47(0.08)^{* *}$ & 0.24 & 0 & 309.8 & -148.9 & 61.57 & $<0.001$ \\
\hline \multirow[t]{2}{*}{ PGLS } & 196 & $-0.45(0.09)^{* *}$ & 0.16 & $0.51(0.39 / 0.87)$ & 293.8 & $-140.9^{\mathrm{a}}$ & 23.09 & $<0.001$ \\
\hline & 196 & $-0.38(0.10)^{* *}$ & 0.17 & 1 & 312.7 & -150.4 & 14.97 & $<0.001$ \\
\hline
\end{tabular}

Cl confidence interval

a the PGLS model is significantly better than the OLS model (likelihood ratio test) ${ }^{* *} P<0.0001$

and that the viviparous taxa generally have lower mSMRs than the oviparous taxa $(t=2.461, d f=194, P=$ 0.015) (Fig. 1). The PGLS model provided a better fit to tSRM or mSMR than the OLS model, as determined by AIC and LRT (Table 1). We therefore used the PGLS model to analyze data. PGLS analysis on tSMR revealed that: 1) the effects of reproductive mode, animal clade and body mass are significant; 2) the mean tSMR is higher in the oviparous taxa than in the viviparous taxa, and is higher in lizards than in snakes; and 3) one of the four interactions is significant (Table 2, Fig. 2a). PGLS analysis on $\mathrm{mSMR}$ revealed that: 1 ) the effects of reproductive mode, animal clade and temperature are significant; 2) the mean mSMR is higher in oviparous species than in viviparous species, and is higher in lizards than in snakes; and 3) none of the four interactions is significant (Table 3, Fig. 2b).

Phylogenetic confirmatory path analyses based on nine candidate path models (Fig. 3) show four directional associations: 1) between body mass and SMR; 2) between SMR

Table 2 ANOVA output of the PGLS model $\{\ln (t S M R) \sim R \times G \times$ $\ln (M)\}$ evaluating the effects of reproductive mode (R), animal clade $(\mathrm{G})$ and body mass (M) on temperature-corrected standard metabolic rate (tSMR)

\begin{tabular}{llllll}
\hline Source & $d f$ & SQ & MSQ & $F$ & $P$-value \\
\hline Reproductive mode & 1 & 0.034 & 0.034 & 24.47 & $<0.001$ \\
Animal clade & 1 & 0.079 & 0.079 & 59.60 & $<0.001$ \\
Body mass & 1 & 2.859 & 2.859 & 2055.56 & $<0.001$ \\
$R \times G$ & 1 & 0.012 & 0.012 & 8.31 & 0.004 \\
$R \times M$ & 1 & 0.002 & 0.002 & 1.64 & 0.202 \\
$G \times M$ & 1 & 0.003 & 0.003 & 2.63 & 0.126 \\
$R \times G \times M$ & 1 & 0.002 & 0.002 & 1.55 & 0.215 \\
Residuals & 188 & 0.261 & 0.001 & & \\
\hline
\end{tabular}

and animal clade; 3) between SMR and reproductive mode; and 4) between temperature and body mass (Fig. 4; Tables 4 and 5). There are positive effects of body mass on SMR, of SMR on reproductive mode, of SMR on animal clade, and of temperature on body mass (Fig. 4; Tables 4 and 5).

\section{Discussion}

Our analyses show that: (1) snakes have lower SMRs (both tSMRs and mSMRs) than do lizards; (2) viviparous species have lower SMRs than do oviparous species; and (3) directional associations between SMR and animal clade or reproductive mode are evident. As elevated SMRs indicate increased costs of maintenance, our results are therefore consistent with the hypothesis that species or taxa with high maintenance costs would be less likely to invest more energy in reproduction or to evolve an energetically expensive mode of reproduction. We were unable to find sex-specific data, but our results still provide an important insight into evolved changes in maintenance costs for the following two reasons. First, although playing their respective sex-specific roles in reproduction, male and female reptiles share important similarities, including SMRs measured in the nonreproductive season. In all metabolic studies of reptiles where adequate data (allowing determination of whether differences in rate exist between sexes) are available, females generally have been found to have either as high or lower metabolic rates than males, with the rates often but not always elevated only when they are gravid [15, 29-31]. Second, reproduction is energetically expensive for females as well as for males and, unlike the endothermic amniotes (mammals and birds), many reptiles have the ability to decouple the time of feeding (energy acquisition) from reproduction (energy expenditure) and rely to a large degree on stored energy rather than currently acquired nutrients to fuel reproduction $[10,16]$. 

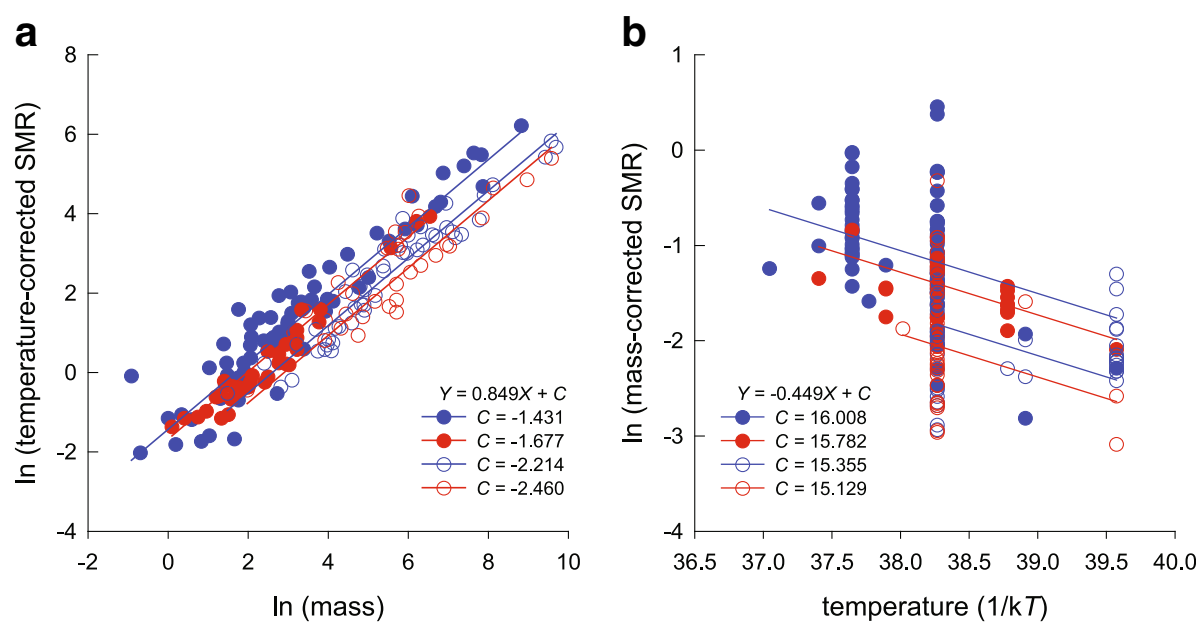

Fig. 2 Metabolic rates of squamate reptiles as a function of body mass (a) or temperature (b). Lines represent PGLS regressions. Filled circles: lizards; open circles: snakes; red line: viviparous species; blue line: oviparous species

Reduced maintenance costs may translate into an increased amount of energy channeled into growth (and thus the increased future reproductive potential), current reproduction, or both. In any case, the energetic savings of reduced maintenance costs will enhance reproduction.

Despite the fact that lizards and snakes are phylogenetically closely related, they differ in many important anatomical, ecological and behavioral characteristics $[16$, 24]. It is therefore not unexpected that they also differ physiologically. Importantly, however, our study shows for the first time that the evolutionary transition from lizard-like to snake-like body form alters maintenance metabolism of the organisms involved. We suggest three hypotheses to explain why snakes have evolved reduced maintenance costs. First, it is less energetically costly to spread body load evenly over the ventral surface as is the case for snakes, than to raise a body off the ground

Table 3 ANOVA output of the PGLS model $\{\ln (m S M R) \sim R \times G \times$ $T\}$ evaluating the effects of reproductive mode (R), animal clade $(\mathrm{G})$ and temperature $(\mathrm{T})$ on mass-corrected standard metabolic rate (mSMR)

\begin{tabular}{llllll}
\hline Source & $d f$ & SQ & MSQ & $F$ & $P$-value \\
\hline Reproductive mode & 1 & 0.014 & 0.014 & 7.32 & 0.007 \\
Animal group & 1 & 0.007 & 0.007 & 3.49 & 0.063 \\
Temperature & 1 & 0.056 & 0.056 & 29.61 & $<0.001$ \\
$R \times G$ & 1 & 0.005 & 0.005 & 2.80 & 0.096 \\
$R \times T$ & 1 & 0.002 & 0.002 & 0.93 & 0.335 \\
$G \times T$ & 1 & $<0.001$ & $<0.001$ & 0.25 & 0.621 \\
$R \times G \times T$ & 1 & 0.003 & 0.003 & 1.62 & 0.205 \\
Residuals & 188 & 0.358 & 0.002 & & \\
\hline
\end{tabular}

with limbs as is the case for most lizards [11]. Second, lizards and snakes have different ratios of surface area to body size (volume or mass) because they differ substantially in body shape. As a positive correlation between the body-mass allometry of metabolic rates and the allometry of body surface area also is present in ectotherms [32], lower maintenance costs may be associated with relatively smaller surface areas in relation to body size in snakes whose body plan is simpler than that of lizards. Third, the difference in relative clutch mass (RCM, a ratio of clutch mass to maternal mass) between lizards and snakes suggests that their responses to selection for this life-history trait differ substantially [12, 13, 16]. Given that there is a trade-off in the energy allocation between maintenance and reproduction, selection would favor the evolution of high RCM in snakes that reduced maintenance costs compared to lizards.

Our study also is the first to demonstrate in squamates that the evolutionary transition in reproductive mode (from oviparous to viviparous reproduction) alters maintenance metabolism. We suggest two explanations for why viviparous species have evolved reduced maintenance costs. First, there may be a high daily energetic cost involved in maintaining young within the body of the female [15]. Thus, even if maintenance costs for oviparous and viviparous species are equal on a daily basis, the longer gestation length of viviparous species still would result in higher energetic costs. Second, females of many viviparous species cease feeding in late stages of pregnancy [16], further increasing energetic constraints on this mode of reproduction. It is clear that, if reproduction is energetically constrained, then a reduction in maintenance costs among viviparous species would reduce this constraint. 

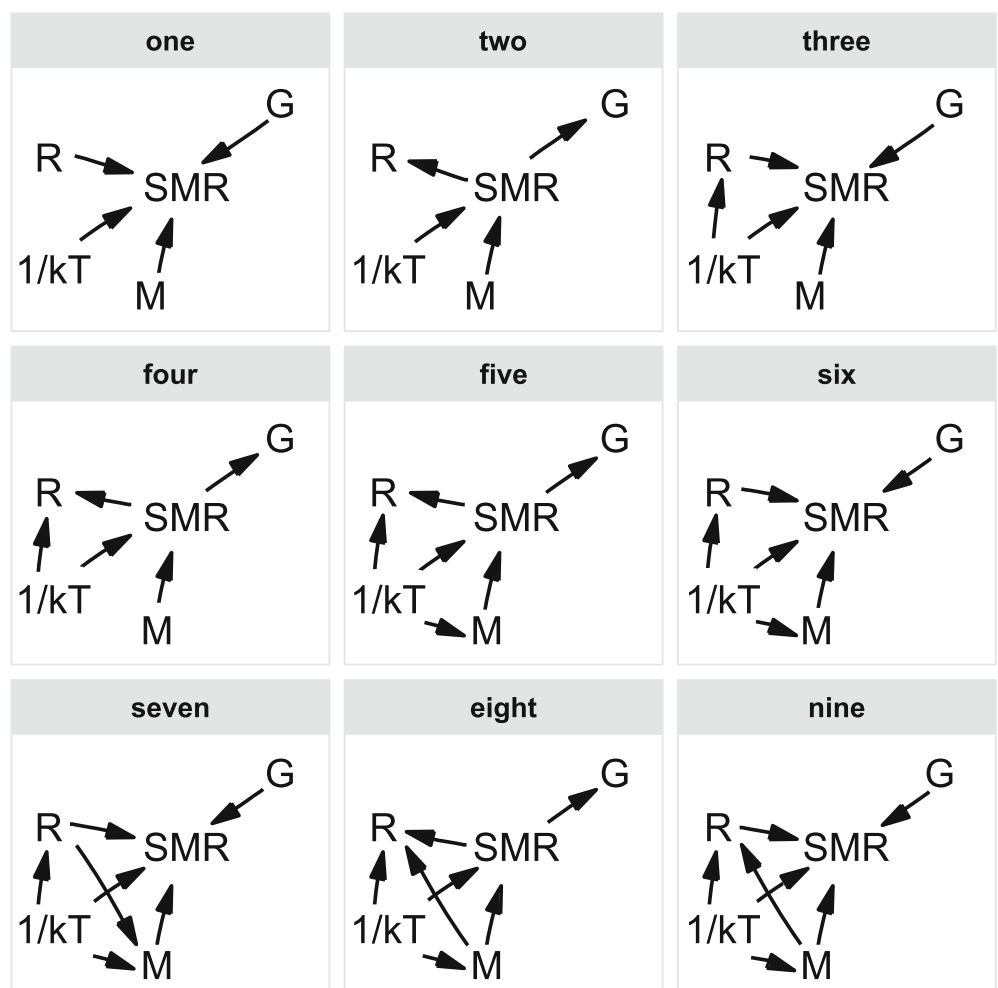

Fig. 3 Directed acyclic graphs representing nine candidate models compared to disentangle the relationships between five traits through phylogenetic confirmatory path analyses and multi-model inference. $M=$ body mass; $S M R=$ standard metabolic rate; $G=$ animal clade (lizards versus snakes); $\mathrm{R}=$ reproductive mode (oviparity versus viviparity); $1 / \mathrm{kT}=1 /$ temperature

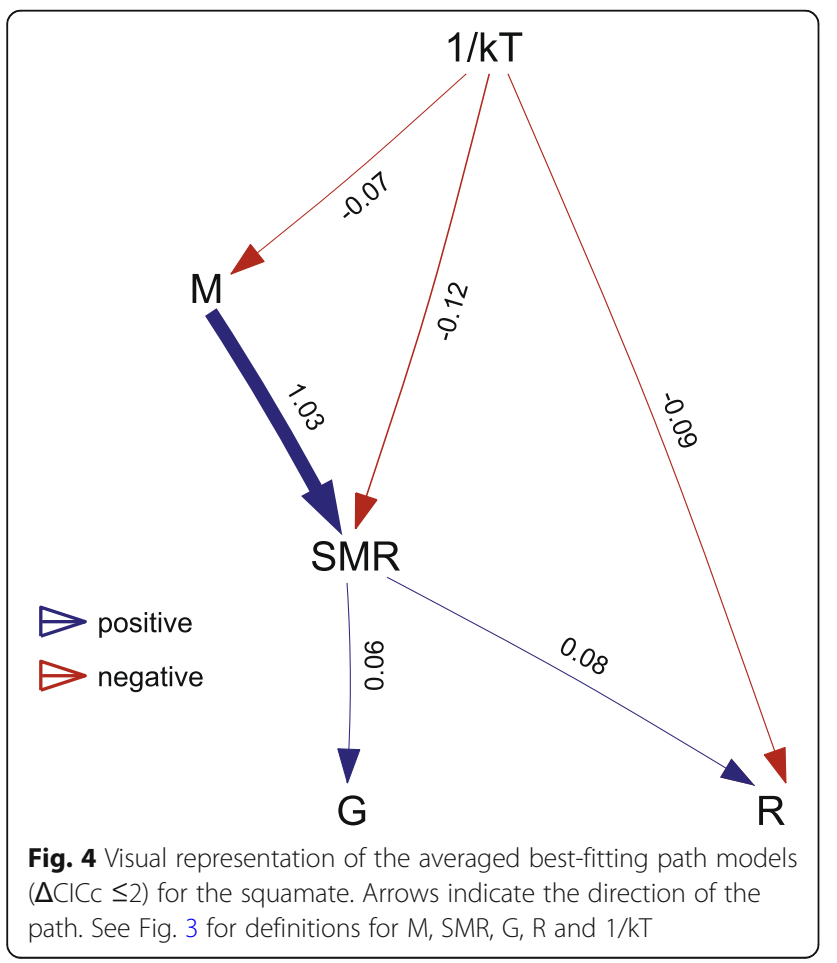

\section{Conclusion}

The transition from lizard-like to snake-like body form and the transition from oviparity to viviparity are major evolutionary transitions in vertebrates, which likely alter many aspects of biology and ecology of the organisms involved [33, 34]. Both transitions are common in squamate reptiles and have occurred repeatedly among

Table 4 Results of the phylogenetic path analyses, ranking the candidate models according to their $\mathrm{ClCc}$ values. The models with $\Delta \mathrm{ClCC}<2$ are in bold

\begin{tabular}{|c|c|c|c|c|c|c|c|}
\hline Model & k & 9 & $C$ & $P$ & $\mathrm{ClCc}$ & $\Delta \mathrm{ClCC}$ & wi \\
\hline five & 4 & 11 & 2.983 & 0.935 & 26.417 & 0.000 & 0.225 \\
\hline eight & 3 & 12 & 1.327 & 0.970 & 27.030 & 0.614 & 0.165 \\
\hline four & 5 & 10 & 6.075 & 0.809 & 27.264 & 0.846 & 0.147 \\
\hline two & 6 & 9 & 9.355 & 0.809 & 27.264 & 1.906 & 0.087 \\
\hline seven & 3 & 12 & 2.765 & 0.672 & 28.323 & 2.052 & 0.081 \\
\hline nine & 3 & 12 & 2.810 & 0.832 & 28.515 & 2.098 & 0.079 \\
\hline three & 5 & 10 & 7.391 & 0.688 & 28.580 & 2.162 & 0.076 \\
\hline one & 6 & 9 & 8.676 & 0.730 & 28.644 & 2.227 & 0.074 \\
\hline six & 4 & 11 & 4.402 & 0.819 & 28.837 & 2.419 & 0.067 \\
\hline
\end{tabular}


Table 5 Path statistics of the average and the best-fitting model from the phylogenetic path analyses in the squamates. For each model, the standardized regression coefficients are listed with their lower and upper 95\% confidence limits. Coefficients with confidence intervals excluding 0 are in bold

\begin{tabular}{lll}
\hline Path & Top model & \\
\hline$M \rightarrow S M R$ & $\mathbf{1 . 0 3 3}$ & {$[\mathbf{0 . 9 7 6} / \mathbf{1 . 0 9 0}]$} \\
$\mathrm{SMR} \rightarrow \mathrm{G}$ & $\mathbf{0 . 0 5 8}$ & {$[\mathbf{0 . 0 5 2} / \mathbf{0 . 0 6 4}]$} \\
$\mathrm{SMR} \rightarrow \mathrm{R}$ & $\mathbf{0 . 0 8 2}$ & {$[\mathbf{0 . 0 4 3 / 0 . 1 2 1 ]}$} \\
$1 / \mathrm{KT} \rightarrow \mathrm{SMR}$ & $-\mathbf{0 . 1 1 9}$ & {$[-\mathbf{0 . 1 6 8} / \mathbf{- 0 . 0 7 0}]$} \\
$1 / \mathrm{KT} \rightarrow \mathrm{R}$ & -0.089 & {$[-0.205 / 0.027]$} \\
$1 / \mathrm{KT} \rightarrow \mathrm{M}$ & -0.07 & {$[-0.182 / 0.042]$} \\
\hline
\end{tabular}

$M$ body mass, SMR standard metabolic rate, $G$ animal group (lizard vs snake), $R$ reproductive mode (oviparous vs viviparous), $1 / k T 1 /$ temperature

closely related species, with fully legged and fully legless species sometimes occurring within the same genus and oviparous and viviparous individuals even within the same species $[33,34]$. That maintenance metabolism relates to body plan (e.g. armored vs. unarmored species [35]) has been discussed in mammals, so has been the relationship between maintenance metabolism and reproductive mode (e.g., marsupial vs. placental species [5], and altricial vs. precocial species [36]). Our study is the first to demonstrate in squamates that evolutionary transitions in body plan (from lizard-like to snake-like body form) and reproductive mode (from oviparous to viviparous reproduction) alter maintenance metabolism.

\section{Additional files}

Additional file 1: Table S1. Lizards (80 oviparous and 35 viviparous species) and snakes (48 oviparous and 33 viviparous species) for which data on standard metabolic rate (SMR, $\left.\mathrm{ml} \mathrm{O}_{2} / \mathrm{h}\right)$, body mass $(\mathrm{g})$ and temperature $\left({ }^{\circ} \mathrm{C}\right.$, at which SMRs were measured) have been available. Reprod mode: O: oviparous; V: viviparous. *: legless lizards. (DOC $481 \mathrm{~kb})$

Additional file 2: Table S2. Parameters of regressions (between tSMR and body mass and between mSMR and temperatures) estimated with ordinary least squares (OLS) and phylogenetic generalized least squares (PGLS) regression models. Cl: confidence interval; ${ }^{* *} P<0.0001$; ${ }^{a}$ the PGLS model is significantly better than the OLS model (likelihood ratio test). (DOC $45 \mathrm{~kb}$ )

Additional file 3: Table S3. ANOVA output of the PGLS model \{ In(tSMR) $\sim R \times G \times \ln (M)\}$ evaluating the effects of reproductive mode $(R)$, animal clade $(\mathrm{G})$ and body mass $(\mathrm{M})$ on temperature-corrected standard metabolic rate (tSMR). (DOC $44 \mathrm{~kb}$ )

Additional file 4: Table S4. ANOVA output of the PGLS model $\{\ln (\mathrm{mSMR})$ $\sim R \times G \times T\}$ evaluating the effects of reproductive mode (R), animal clade (G) and temperature (T) on mass-corrected standard metabolic rate (mSMR). (DOC $38 \mathrm{~kb})$

Additional file 5: Table S5. Results of the phylogenetic path analyses, ranking the candidate models according to their $\mathrm{ClCc}$ values. The models with $\Delta \mathrm{ClCc}<2$ are in bold. (DOC $43 \mathrm{~kb}$ )

Additional file 6: Table S6. Path statistics of the average and the bestfitting model from the phylogenetic path analyses in the squamates. For each model, the standardized regression coefficients are listed with their lower and upper 95\% confidence limits. Coefficients with confidence intervals excluding 0 are in bold. (DOC 34 kb)

\section{Abbreviations}

AIC: Akaike's Information Criterion; ANOVA: Analysis of variance: CICc: C-statistic Information Criterion; LRT: Likelihood-ratio test; mSMR: Mass-corrected standard metabolic rate; OLS: Ordinary least squares regression; PGLS: Phylogenetic generalized least squares regression; RCM: Relative clutch mass; SMR: Standard metabolic rate; tSMR: Temperature-corrected standard metabolic rate

\section{Acknowledgements}

We thank Fang Yang for assistance in the collection of data.

\section{Funding}

This study was funded by the National Natural Science Foundation of China (31470471, 31301878, 31300339 and 31272294), Natural Science Foundation of Jiangsu Province (BK20161556), Priority Academic Program Development of Jiangsu Higher Education Institutions, Innovation Program of Jiangsu Province for Graduate Students (KYLX_0715), and Cultivation Program for Excellent Doctoral Students of Nanjing Normal University.

\section{Availability of data and materials}

The datasets supporting the conclusions of this article are included within the article and its Additional file 1.

\section{Authors' contributions}

$X J$ and $L Z$ conceived and designed the study. LZ, KG, GZZ and LHL collected and analyzed the data. LZ and XJ wrote the paper. All authors contributed to manuscript revisions, approved the final version of the manuscript for publication, and agreed to be held accountable for the content of this manuscript.

\section{Ethics approval}

No ethics approval was required for this research.

\section{Consent for publication}

Not applicable.

\section{Competing interests}

The authors declare that they have no competing interests.

\section{Publisher's Note}

Springer Nature remains neutral with regard to jurisdictional claims in published maps and institutional affiliations.

\section{Author details}

${ }^{1}$ Jiangsu Key Laboratory for Biodiversity and Biotechnology, College of Life Sciences, Nanjing Normal University, Nanjing, Jiangsu 210023, China. ${ }^{2}$ Hangzhou Key Laboratory for Animal Adaptation and Evolution, College of Life and Environmental Sciences, Hangzhou Normal University, Hangzhou, Zhengjiang 310036, China.

Received: 7 December 2017 Accepted: 22 March 2018 Published online: 03 April 2018

\section{References}

1. Brown JH, Gillooly JF, Allen AP, Savage VM, West GB. Toward a metabolic theory of ecology. Ecology. 2004;85:1771-89.

2. Glazier DS. Is metabolic rate a universal 'pacemaker' for biological processes? Biol Rev. 2015;90:377-407.

3. Congdon JD, Dunham AE, Tinkle DW. Energy budgets and life histories of reptiles. In: Gans C, editor. Biology of the Reptilia, vol. 13. New York: Academic Press; 1982. p. 233-71.

4. Lucas A. Bioenergetics of aquatic animals. London: Taylor and Francis Ltd; 1996.

5. McNab BK. The physiological ecology of vertebrates: a view from energetics. Ithaca: Comstock Publishing Associates; 2002.

6. Sibly RM, Grimm V, Martin BT, Johnston ASA, Kułakowska K, Topping CJ, Calow P, Nabe-Nielsen J, Thorbek P, DeAngelis DL. Representing the 
acquisition and use of energy by individuals in agent-based models of animal populations. Methods Ecol Evol. 2013;4:151-61.

7. Glazier DS. Resource-allocation rules and the heritability of traits. Evolution. 2002:56:1698-700

8. Glazier DS. Resource allocation patterns. In: Rauw WM, editor. Resource allocation theory applied to farm animal production. Wallingford: $C A B$ International; 2009. p. 22-43.

9. Kubička L, Kratochvíl L. First growth, then breed and finally get fat: hierarchical allocation to life-history traits in a lizard with invariant clutch size. Funct Ecol. 2009;23:595-601.

10. Luo LG, Ding GH, Ji X. Income breeding and temperature-induced plasticity in reproductive traits in lizards. J Exp Biol. 2010;213:2073-8.

11. Seigel RA, Fitch HS. Ecological patterns of relative clutch mass in snakes. Oecologia. 1984;61:293-301.

12. Shine R. Relative clutch mass and body shape in lizards and snakes: is reproductive investment constrained or optimized? Evolution. 1992;46:828-33.

13. Shine R, Schwarzkopf $L$. The evolotion of reproductive effor in lizards and snakes. Evolution. 1992;46:62-75.

14. Feldman A, Bauer AM, Castro-Herrera F, Chirio L, Das I, Doan TM, Maza E, Meirte D, de Campos NC, Nagy ZT, Torres-Carvajal O, Uetz P, Meiri S. The geography of snake reproductive mode: a global analysis of the evolution of snake viviparity. Glob Ecol Biogeogr. 2015;24:1433-42.

15. Foucart T, Lourdais O, DeNardo DF, Heulin B. Influence of reproductive mode on metabolic costs of reproduction: insight from the bimodal lizard Zootoca vivipara. J Exp Biol. 2014;217:4049-56.

16. Shine R. Life-history evolution in reptiles. Annu Rev Ecol Evol Syst. 2005; 36:23-46.

17. R Development Core Team. R: a language and environment for statistical computing. Vienna: R Foundation for Statistical Computing. http://www.Rproject.org; 2015.

18. Harrell FE, Jr. rms: Regression Modeling Strategies. R package version 4.3-0, Available from: http://CRAN.R-project.org/package=rms; 2015. Accessed 28 July 2015.

19. Orme, D., Freckleton, R., Thomas, G., Petzoldt, T., Fritz, S., Isaac, N. \& Pearse, W. The caper package: Comparative analysis of phylogenetics and evolution in R. https://cran.r-project.org/web/packages/caper/index.html; 2013. Accessed 16 Sept 2013.

20. Warne RW, Charnov EL. Reproductive allometry and the size-number tradeoff for lizards. Am Nat. 2008;172:E80-98.

21. Maddison WP, Maddison DR. Mesquite: a modular system for evolutionary analysis. Version 3.04. http://mesquiteproject.org; 2015. Accessed 25 Oct 2015.

22. Pyron RA, Burbrink FT, Wiens JJ. A phylogeny and revised classification of Squamata, including 4161 species of lizards and snakes. BMC Evol Biol. 2013;13:93.

23. Martins $\mathrm{E}$, Garland T. Phylogenetic analyses of the correlated evolution of continuous characters: a simulation study. Evolution. 1991;45:534-57.

24. Freckleton RP, Harvey PH, Pagel M. Phylogenetic analysis and comparative data: a test and review of evidence. Am Nat. 2002;160:712-26.

25. Pagel M. Inferring the historical patterns of biological evolution. Nature. 1999:401:877-84

26. von Hardenberg A, Gonzalez-Voyer A. Disentangling evolutionary causeeffect relationships with phylogenetic confirmatory path analysis. Evolution. 2013;67:378-87.

27. Pyron R, Burbrink FT. Early origin of viviparity and multiple reversions to oviparity in squamate reptiles. Ecol Lett. 2014;17:13-21.

28. van der Bijl W. phylopath: Perform phylogenetic path analysis. https://cran.rproject.org/web/packages/phylopath/index.html; 2017. Accessed 18 Nov 2017.

29. Bennett AF, Dawson WR. Metabolism. In: Gans C, Dawson WR, editors. Biology of the Reptilia, vol. 5. New York: Academic Press; 1976. p. 127-223.

30. Ladyman M, Bonnet X, Lourdais O, Bradshaw D, Naulleau G. Gestation, thermoregulation, and metabolism in a viviparous snake, Vipera aspis: evidence for fecundity-independent costs. Physiol Biochem Zool. 2003; 76:497-510

31. Lourdais O, Guillon M, DeNardo D, Blouin-Demers G. Cold climate specialization: adaptive covariation between metabolic rate and thermoregulation in pregnant vipers. Physiol Behav. 2013;119:149-55.

32. Hirst AG, Glazier DS, Atkinson D. Body shape shifting during growth permits tests that distinguish between competing geometric theories of metabolic scaling. Ecol Lett. 2014;17:1274-81.
33. Griffith OW, Blackburn DG, Brandley MC, Van Dyke JU, Whittington CM, Thompson MB. Ancestral state reconstructions require biological evidence to test evolutionary hypotheses: a case study examining the evolution of reproductive mode in squamate reptiles. J Exp Zool B. 2015:324:493-503.

34. Wiens JJ, Slingluff JL. How lizards turn into snakes: a phylogenetic analysis of body-form evolution in angiud lizards. Evolution. 2001;55:2303-18.

35. Lovegrove BG. The evolution of body armor in mammals: plantigrade constraints of large body size. Evolution. 2001;55:1464-73.

36. Genouda M, Voge P. Energy requirements during reproduction and reproductive effort in shrews (Soricidae). J Zool. 1990;220:41-60

\section{Submit your next manuscript to BioMed Central and we will help you at every step:}

- We accept pre-submission inquiries

- Our selector tool helps you to find the most relevant journal

- We provide round the clock customer support

- Convenient online submission

- Thorough peer review

- Inclusion in PubMed and all major indexing services

- Maximum visibility for your research

Submit your manuscript at www.biomedcentral.com/submit
Biomed Central 